Ryszard Kozakiewicz*

\title{
Possible Use of Spatial Information Listed in INSPIRE Directive in Environmental Impact Assessment**
}

\section{Introduction}

The environmental impact assessment (EIA) has become a permanent element of each planning and investment process. In case of the majority of activities of potential environmental impact the decision-making procedures assume early identification and assessment of risks. A significant limitation for the common and efficient execution of environmental assessments may be associated with obstacles in terms of access to information on the environment, arising from technical, legal, organisational and financial factors. In order to increase the efficiency of management at all levels of administration and provide free access to environmental data for EU citizens, based on the provisions of the INSPIRE directive [3], the spatial information infrastructure is created (IIP). Its main role is to streamline the resources of spatial information, facilitate and accelerate the performance of administration at all levels and to make information on environmental quality and values available to the society.

Due to the broad scope of environmental analyses conducted while executing the environmental impact assessment, access to the consistent database describing the most important environmental components should be considered as the key element of their effectiveness as a tool of environmental management.

However, for the efficient use of data for the needs of EIA it is necessary to fulfil the following conditions:

- providing for temporal and spatial coherence of the information;

- correlating the content of individual thematic layers with formal requirements referring to the scope of the EIA, associating the amendments of law in both areas;

- determining the scope of metadata allowing for searching and aggregation of information in terms of implementation of the environmental impact assessment process (and, at a longer-term perspective, application of decision support algorithms for this purpose).

* AGH University of Science and Technology, Faculty of Mining Surveying and Environmental Engineering, Department of Environmental Management and Protection, Krakow, Poland

** The paper has been prepared within the scope of the AGH UST statutory research no. 11.11.150.008 
The first condition is fulfilled directly through appropriate implementation of provisions of INSPIRE directive within which the high quality and consistence of information is one of the basic assumptions. For the effective use of spatial information resources by persons performing the environmental impact assessment it is, however, necessary to consider the specific nature of the process and the EIA procedures. In this article, the specification of the planned content of IIP thematic layers is combined with the demand for information within the EIA procedures.

\section{Environmental Components Analysed in Environmental Impact Assessment}

The proceedings commonly known as "environmental impact assessment" refer to two main cases:

1) the so-called "strategic assessment" where effects of implementation of strategic and planning documents are subject to analysis (management plans, development programmes of main economic sectors, development strategies);

2) "assessment for projects" in which environmental effects of implementation of specific investment projects are usually analysed ${ }^{1}$.

In both cases, irrespective of procedural differences, the assessment is based on a common model of the environment.

The Act on "Availability of information on environment and its protection, public participation in environmental protection and environmental impact assessment" of 2008 [10] specifies the required scope of environmental components the impact on which should be analysed within the EIA procedure. The requirements are determined in "Section IV" for strategic assessment and in "Section V" - for "projects". The expected level of detail is different in both cases, however, the scope of impacts necessary to consider is similar.

For strategic assessments the level of detail is provided in Art. 51 of the aforementioned Act:

[the forecast contains] foreseen significant impacts [...] on the environment, in particular, on:

- biodiversity,

- human beings,

- animals,

- plants,

- water,

- air,

- Earth surface,

- landscape,

- climate,

${ }^{1}$ The document summarising the detailed environmental impact assessment for strategic assessments is known as a "Forecast", whereas the analogical document for assessment for the projects is called a "Report". 
- natural resources,

- monuments,

- material goods,

including the correlations between these environmental elements and between impacts on these elements;

Within the assessment of environmental impacts of implementation of projects it is required to (Art. 66):

justify the variant proposed by the applicant, indicating its environmental impact, in particular on:

a. people, plants, animals, mushrooms and natural settlements, water and air,

b. ground surface, considering the mass movements of the earth, the climate and the landscape,

c. material goods,

d. monuments and cultural landscape, covered by the existing documentation, in particular, the register of monuments.

The scope and level of detail of the analyses increases with almost every amendment of law and guidelines on execution of the assessments. It is associated with harmonisation of the scope of impact assessment in the EU Member States as well as the strive for enhancement of precision and reliability of the reports. Special attention is paid to assessment of secondary, indirect and cumulative impacts $[4,6]$. The required analyses often refer to areas of knowledge overlapping with various fields of science, so far weakly examined, which require development of a common standpoint by experts representing various disciplines. Rarely may the assessment be based on the commonly accepted model of the environment, considering the simultaneous interaction (accumulation) of many types of impacts.

An essential, often referred to in literature, weakness of the EIA reports and forecasts is often a narrow, sectoral approach to environmental impacts. The reports are often limited to summarising the quantitative impacts on individual components, without multi-criteria analysis, and also without considering the secondary and synergic impacts. One of the factors responsible for this situation is the lack of a common platform for information exchange among specialists representing various disciplines, working on the assessment with the use of separate models, mapping overlays and information layers.

\section{Using the IIP Thematic Layers at Successive Stages of the EIA Procedures}

Nowadays, fast development of generally accessible information resources on the environment is ongoing. The assumed interoperability of the system determines high standards in terms of adjustment of the scope and level of detail of the information to the needs of the recipients. 
The possibilities to use the information managed in IIP for execution of the environmental impact assessment are associated with relevant preparation of the data. In order to enhance the attractiveness of the system for the EIA performers appropriate grouping of the information would be recommended (or creation of overlays enabling its semi-automatic grouping) into clusters corresponding directly to the issues stipulated by legal regulations for the EIA procedures. The recommendation of a broad approach to indirect, secondary and synergic impacts, highlighted in the directives and recommendations of the European Commission is associated with the need to consider many thematic layers and environmental models within the assessment process.

In the environmental impact assessment, traditionally, four stages of procedure are specified:

- verification of significance of the impacts (screening),

- determining the scope of the assessment (scoping),

- detailed assessment,

- post-implementation assessment.

The amendment to the "EIA Directive" [9], the draft of which is currently (2013) subject to the last stage of consultations, significantly raises the role of the preliminary project verification stage (screening). The level of detail of the procedure is to be increased, maintaining its common nature.

The resources of the environmental information system, constituting a part of the spatial information infrastructure, will be used at each stage of the EIA procedure, however, the method and scope of utilisation of the data at individual stages shall differ significantly.

\section{Verification of the significance of the impacts (screening)}

At this stage preliminary assessment of potential environmental noxiousness is performed and the decision is taken on the necessity and level of detail of further stages of the procedure. It is recommended to compare the project assessed with similar projects implemented in the past as well as to identify and perform the preliminary assessment of local conditions, associated, for example with the existence of nearby facilities particularly sensitive to pressure. The preliminary assessment of importance of individual environmental impacts is performed, including reference (as much as possible) to threshold values, identification of potential social conflicts generated by the project.

As a result of the first stage, the relevant path of further environmental impact assessment procedure is attributed. The stage requires fast assessment of the project, usually based on rather limited data resources. However, the decision taken by the authority should contain justification, both in case of the recommendation and resignation from detailed assessment. At this stage the spatial information system, adjusted to the needs of the EIA procedure, is the key factor ensuring the efficiency 
of the process. The availability and validity of spatial data improves the speed and adequacy of the decision taken, whereas the lack of correlation between the development of the IIP and the EIA system shall significantly reduce the effectiveness of actions undertaken by the administration.

\section{Determining the scope of the assessment (scoping)}

The classification of the project to the stage of detailed assessment is followed by the determination of the scope of assessment. The environmental values and resources are indicated for which the impacts have to be analysed in detail, including the nature of impacts to be considered. The spatial scope of the analyses is also specified. Whereas screening bears the properties of a scientific study (it requires the preliminary assessment of significance of the impacts), scoping is an element of the administrative procedure determining the requirements for documentation needed to issue the relevant environmental decisions.

At this stage often the appearance of key words in the preliminary description of the subject of the decision issued, or exceeding e.g. of emission thresholds or the size of facilities and installations, results in determination of routine recommendations for the detailed assessment. The use of spatial information at this stage shall be mainly limited to identification of facilities and areas particularly sensitive to pressure (e.g. facilities and areas under protection, locations where children and teenagers stay, settlements important for the EU, etc.) within the area of the potential significant impact of the intended initiatives. However, it should be noticed that the notion of "environment" used in the EIA is very broad, covering the living and inanimate nature, the society (including health), cultural values (including monuments), material goods, natural resources (including minerals). Therefore, while determining the scope of the assessment information attributed to various thematic layers should be considered. This task can be considerably facilitated by the development of a collection of metadata enabling "intelligent searching" and semi-automatic analyses.

\section{Detailed assessment}

The stage covers field and laboratory studies and modelling (among others, dispersion of pollutants). During the detailed assessment quantitative analyses are conducted, often at a considerable level of detail. Also at this stage, wide use of information managed in the spatial information infrastructure should be expected. At a first instance, information for the needs of spatial analyses and data feeding the models of dispersion of pollutants and noxious factors in the environment (air and water pollutants, noise) shall be downloaded. This shall include, for example, data on area topography and management, geology, hydrological and meteorological conditions. At the next stage, under the condition of appropriate preparation of information layers, information for multi-criteria analyses and for the assessment of cumulative and secondary effects, may be downloaded. 


\section{Post-implementation assessment}

This stage is aimed at verification of the adequacy of environmental models used in detailed assessments and to determine real impact of the project on the environment. Monitoring studies are conducted as recommended in the decision or at the stage of the detailed assessment, or the full ex-post assessment is performed ${ }^{2}$.

This stage rather supplies the external information resources than use them. The results of the post-implementation assessment and monitoring of changes in the environment provide basis for more efficient performance of the preliminary classification of significance of impacts (screening) for the subsequent investments.

The speed and quality of the first two stages of the EIA procedure depends on the availability, easiness of searching and reliability of information on the environment. At present the construction of the spatial information infrastructure of the EU can be considered as the most important factor which may accelerate the EIA procedures, reduce their costs and increase trust in administrative decisions taken on their basis (a possibility of independent verification based on common information resources).

Within the execution of the detailed assessment, coherent and valid resources of environmental information will reduce the time of performing the assessment. The discussion between parties involved in the assessment process, i.e. the contractor, the investor, the authorities and the society, will be facilitated. The key factor is to base the decision on a common, coherent information resources. At this stage of consultations, the society will have access to almost identical scope of environmental data as the executors of the assessment and the authority issuing the decisions. One of the main objectives of the EIA procedure is to reach the consensus among all parties to the procedure in the scope of valuation of environmental, economic and social goods.

Whereas at the first three stages of the EIA procedure the data is mainly acquired from external resources, the stage of post-implementation assessments supplies new information to the resources. Verification of the applied models, initial conditions and conclusions contained in the previous assessments is performed. Introduction of the feedback on the quality of the EIA procedure increases the social trust towards the assessment system. The studies of the real impact of a project already implemented make it possible to supply the information system with the data allowing for building the impact models at a supra-local scale.

\section{Demand for Information in the EIA Process}

The construction of the spatial information infrastructure is an ambitious project the implementation of which (under the current form) is planned over the whole decade $^{3}$. However, the problem is much broader than creating only the infrastructure

\footnotetext{
2 In accordance with the proposal on EIA directive amendment (2012) [4] the role and common use of ex-post assessment shall increase significantly.

3 In accordance with the current schedule up to 2019.
} 
for acquisition, management and making the information available. The overall philosophy of using the spatial information, so far available mainly in the form of printed or sketched maps, should be subject to detailed analysis and reconstruction. Good cartographic practices were improved over centuries, adjusting to the technical progress in the scope of field surveys and printing techniques. However, the progress was slow enough to leave time for in-depth analysis of recipients' needs, perception possibilities, or even considering the social effects of changes. Currently, the pace of technical progress in the scope of information management considerably exceeds the possibilities of conscious development of requirements in this scope, considering the optimal exploitation of tools and resources by various groups of recipients.

An exceptionally broad scope of the environmental impact assessment causes that individual issues are often elaborated by experts or teams working independently. In case the specific thematic layer is used by experts of various disciplines, the adjustment of its information content (and the metadata collection) is particularly important for its usefulness, in terms of variable specifics of the problems solved, often associated with habits and trade traditions. For example, the layer "Transport Networks", during the environmental assessment, may be used simultaneously by natural scientists, experts on air pollution, noise, soil stability, landscape designers, hydrologists, health experts, experts on effects of disasters or climate changes. If each of them recognises the layer as useful for own analyses, not only the information exchange platform will be created but possibilities of analyses shall be open in relation to secondary effects, indirect effects and cumulative impacts. Supplementing the description of the layer, e.g. with information concerning the level of environment fragmentation by individual sections of the network, vegetation growing in the road or railway corridor, traffic intensity, number and sites of accidents, number of animals knocked down by vehicles, etc., on the one hand, shall facilitate the EIA process and on the other hand, it will constitute an important factor of social discussion on the criteria of decisions affecting the environment. At the same time, the role of spatial information as the ecological education tool shall increase (diverse aspects of the projects implemented will be displayed).

The Table 1 presents the importance of the thematic layers envisaged within the IIP for implementation of the environmental impact assessments in the scope determined by the act. In the matrix, "reference layers" were separated, providing background for environmental impact assessment (reference layers) and directly used in analyses, including their role in assessment of the impact on the specific environmental component.

Layers which may be potentially used by many trade teams include: transport networks, topography of the territory, spatial management, zones of natural hazards, atmospheric conditions, energy resources. They require a particularly broad analysis in terms of recipients' demand for information, preferable forms of its acquisition and the possibility to improve work by information searching and decision support systems arising from new technological solutions. 
It should be remembered that works are still ongoing concerning both the technical details and the content of thematic layers of IIP $[1,2,5]$, as well as the improvement of the environmental impact assessment system [7]. It may be expected that new challenges and problems will appear on the interface of both areas, for example in connection with the independent amendment of legal regulations referring to them. On the other hand, the simultaneous modernisation of both correlated tools, essential for environmental management, provides the opportunity to improve and synchronise both processes.

In connection with the development of cheap, highly efficient technologies of environmental monitoring and imaging [8], we face the flow of raw measurement data which has never been found before. Its optimal exploitation is currently becoming the most important technological challenge. Environmental impact assessment, with its complexity and interdisciplinary nature, is an excellent testing plot for research in this area.

Table 1. Scope of utilisation of IIP thematic layers in the development of the impact assessment on individual environmental components

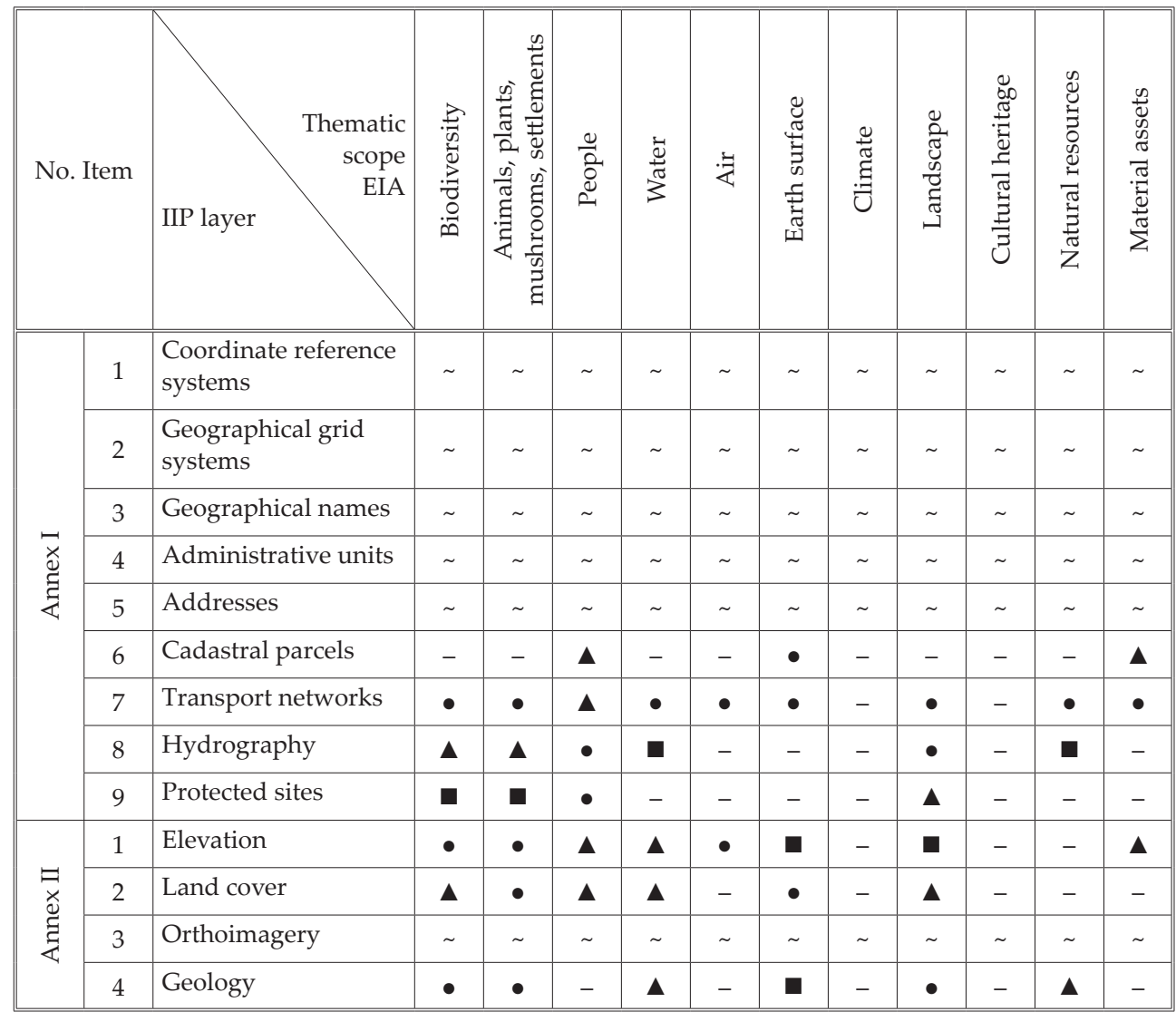


Table 1. cont.

\begin{tabular}{|c|c|c|c|c|c|c|c|c|c|c|c|c|c|}
\hline & 1 & Statistical units & ( $\sim$ & ( & $\sim$ & 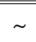 & $\bar{~} \sim$ & $\sim$ & $\bar{~} \sim$ & $\sim$ & 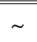 & 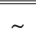 & $\sim$ \\
\hline & 2 & Buildings & - & - & $\Delta$ & - & $\bullet$ & - & - & $\Delta$ & $\Delta$ & & च \\
\hline & 3 & Soil & $\bullet$ & $\Delta$ & - & - & - & $\bullet$ & $\bullet$ & - & - & घ & $\bullet$ \\
\hline & 4 & Land use & $\Delta$ & $\bullet$ & $\Delta$ & $\Delta$ & $\Delta$ & • & $\Delta$ & घ & - & $\bullet$ & 口 \\
\hline & 5 & Human health and safety & - & - & घ & - & $\bullet$ & - & - & - & - & - & - \\
\hline & 6 & $\begin{array}{l}\text { Utility and governmental } \\
\text { services }\end{array}$ & - & - & $\Delta$ & $\bullet$ & $\bullet$ & - & - & - & - & - & - \\
\hline & 7 & $\begin{array}{l}\text { Environmental } \\
\text { monitoring facilities }\end{array}$ & - & - & $\bullet$ & $\bullet$ & $\bullet$ & - & - & - & - & - & - \\
\hline & 8 & $\begin{array}{l}\text { Production and industrial } \\
\text { facilities }\end{array}$ & - & - & $\bullet$ & $\bullet$ & $\bullet$ & - & $\bullet$ & $\Delta$ & - & - & $\boldsymbol{\Delta}$ \\
\hline & 9 & $\begin{array}{l}\text { Agricultural and } \\
\text { aquaculture facilities }\end{array}$ & $\boldsymbol{\Delta}$ & $\boldsymbol{\Delta}$ & - & $\bullet$ & - & - & $\bullet$ & $\Delta$ & - & - & $\Delta$ \\
\hline$\exists$ & 10 & $\begin{array}{l}\text { Population distribution } \\
\text { - demography }\end{array}$ & $\bullet$ & $\bullet$ & $\Delta$ & $\bullet$ & $\bullet$ & - & - & $\bullet$ & - & - & $\bullet$ \\
\hline 壳 & 11 & $\begin{array}{l}\text { Area management / } \\
\text { restriction/ regulation } \\
\text { zones and reporting units }\end{array}$ & - & - & $\boldsymbol{\Delta}$ & $\boldsymbol{\Delta}$ & $\bullet$ & - & - & - & - & • & $\bullet$ \\
\hline & 12 & Natural risk zones & $\Delta$ & $\bullet$ & 口 & $\Delta$ & - & घ & - & - & $\bullet$ & $\bullet$ & - \\
\hline & 13 & Atmospheric conditions & $\Delta$ & $\Delta$ & - & $\bullet$ & $\Delta$ & $\bullet$ & - & - & - & $\bullet$ & - \\
\hline & 14 & $\begin{array}{l}\text { Meteorological } \\
\text { geographical features }\end{array}$ & $\bullet$ & $\bullet$ & - & $\bullet$ & - & - & - & - & - & $\bullet$ & - \\
\hline & 15 & $\begin{array}{l}\text { Oceanographic } \\
\text { geographical features }\end{array}$ & $\boldsymbol{\Delta}$ & $\bullet$ & - & $\bullet$ & - & - & - & - & - & • & - \\
\hline & 16 & Sea regions & 口 & $\bullet$ & - & - & - & - & - & - & - & $\bullet$ & - \\
\hline & 17 & Bio-geographical regions & $\boldsymbol{\square}$ & $\bullet$ & - & - & - & - & - & - & - & $\bullet$ & - \\
\hline & 18 & Habitats and biotopes & 口 & 口 & - & - & - & - & - & $\bullet$ & - & $\bullet$ & - \\
\hline & 19 & Species distribution & $\mathbf{\square}$ & 口 & - & - & - & - & - & - & - & $\bullet$ & - \\
\hline & 20 & Energy resources & $\bullet$ & $\Delta$ & - & $\Delta$ & - & $\bullet$ & $\bullet$ & $\bullet$ & - & 口 & $\bullet$ \\
\hline & 21 & Mineral resources & - & - & - & - & - & - & - & - & - & 口 & $\bullet$ \\
\hline
\end{tabular}

The columns contain environmental components for which impacts are analysed in accordance with the "EIA Act" [10].

In the rows, IIP layers are provided, which are determined in the subsequent Annexes to the INSPIRE Directive [2].

Role of a layer in impact assessment on the specific environmental component:

— - key, $\boldsymbol{\Lambda}$ - significant, $\bullet$ - supplementary, - reference layer., - - irrelevant

\section{References}

[1] Bieda A., Bydłosz J., Parzych P.: Actualization of data concerning surface flowing waters, based on INSPIRE directive requirements. Geomatics and Environmental Engineering, vol. 7, no. 1, 2013, pp. 25-36.

[2] Chojka A.: Badanie i ocena zgodności z INSPIRE. Roczniki Geomatyki, t. 11, 2013, pp. 25-32. 
[3] Directive 2007/2/EC of the European Parliament and the Council of 14 March 2007 r. establishing an Infrastructure for Spatial Information in the European Community (INSPIRE). OJ EU L 25.4.2007 108/1.

[4] Directive of the European Parliament and the Council no. 2011/92/EU of 13 December 2011 on the assessment of the effects of certain public and private projects on the environment. OJ EU L 28.1.2012 26/1, consolidated text.

[5] Gaździcki J.: Infrastruktura informacji przestrzennej w świetle doświadczeń wdrożeniowych w Polsce. Roczniki Geomatyki, t. 11, 2013, pp. 7-13.

[6] Guidelines concerning the EIA: Environmental Impact Report verification. The Publications Office of the European Union, European Communities, 2001.

[7] Kozakiewicz R.: Nowelizacja dyrektywy OOŚ - nowe wyzwania w zakresie wykorzystania zasobów danych przestrzennych. Roczniki Geomatyki, t. 12, 2014, pp. 401-410.

[8] Mikrut S., Głowienka-Mikrut E., Michałowska K.: The UAV technology as a future-oriented direction in the development of low-ceiling aerial photogrammetry. Geomatics and Environmental Engineering, vol. 7, no. 4, 2013, pp. 69-77.

[9] Proposal of the European Commission - Directive of the European Parliament and the Council amending Directive 2011/92/EU on the assessment of the effects of certain public and private projects on the environment. COM(2012) 628 final, 26.10.2012, 2012/0297 (COD).

[10] Ustawa z dnia 3 października 2008 r. o udostępnianiu informacji o środowisku i jego ochronie, udziale społeczeństwa w ochronie środowiska oraz o ocenach oddziaływania na środowisko. Dz.U. 2013, poz. 1235, consolidated text, Dz.U. 2008 nr 199 poz. 1227. 